\title{
ECRH on CFETR - physics and technology needed
}

\author{
Jiangang Li, F.K. Liu, Y.P. Zhao, X.J. Wang, M.H. Li, H.D. Xu \\ Institute of Plasma Physics, Chinese Academy of Sciences, Hefei, China (j_li@ipp.ac.cn)
}

The Chinese Fusion Engineering Testing Reactor (CFETR) is the next device for the Chinese magnetic confinement fusion (MCF) program which aims to bridge the gaps between the fusion experiment ITER and the demonstration reactor DEMO. CFETR will be operated in two phases: Steady-state operation and tritium selfsustainment will be the two key issues for the first phase with a modest fusion power up to $200 \mathrm{MW}$. The second phase aims for DEMO validation with a fusion power around $1 \mathrm{GW}$.

Operation scenarios have been assessed by integrated modeling based on advanced H-mode physics with high magnetic fields (up to $7 \mathrm{~T}$ ). High frequency electron cyclotron resonance heating $(170-230 \mathrm{GHz})$, lower hybrid current drive (5-7.5 GHz), off-axis negative-ion neutral beam injection will be used together with high bootstrap current for achieving steady-state advanced operation.

Fully non-inductive CFETR scenarios have been developed with a self-consistent core-pedestal-equilibrium model. Table one is the baseline scenarios based on the integrated modeling. Different modelling of steady state operation conditions by the combination of ECCD with NNBI, ECCD with high field lower hybrid wave current drive were presented in this paper.

Concept design for CFETR EC system which is $20 \mathrm{MW} 170 \mathrm{GHz}$ from mid-plan port and $230 \mathrm{GHz}$ from top window depending on the operation scenarios. $750 \mathrm{kA}-$ 1.5 MA plasma current can be driven by chosen different location and rotation angle. Further optimization for get the best current drive condition is still under way.

Table. Baseline steady state scenarios for CFTER

\begin{tabular}{|l|c|c|c|}
\hline & Start point & Phase I & Phase II \\
\hline $\mathrm{R}_{0}, \mathrm{a}(\mathrm{m})$ & $6.6,1.8$ & $6.6,1.8$ & $6.6,1.8$ \\
\hline $\mathrm{P}_{\mathrm{NBI}}, \mathrm{P}_{\mathrm{ECH}}(\mathrm{MW})$ & $29.5,1.0$ & $35.8,20.0$ & $33.9,20.1$ \\
\hline Fusion Gain $\mathrm{Q}_{\mathrm{FUS}}$ & 2.9 & 3.0 & 14.9 \\
\hline $\mathrm{r} \mathrm{P}_{\text {fus }}(\mathrm{MW})$ & 111 & 169 & 811 \\
\hline $\mathrm{B}_{\mathrm{T}}(\mathrm{T}), \mathrm{I}_{\mathrm{p}}(\mathrm{MA})$ & $6.0,7.5$ & $6.0,7.6$ & $6.0,10.0$ \\
\hline $\left.\mathrm{B}_{0}\right)$ tstrap Fraction & $60 \%$ & $63.6 \%$ & $84.4 \%$ \\
\hline $\boldsymbol{\beta}_{\mathrm{N}}$ & 1.46 & 1.89 & 3.15 \\
\hline $\mathrm{H}_{98 \mathrm{Y} 2}$ & 1.3 & 1.3 & 1.3 \\
\hline$\Gamma_{\mathrm{NW}}\left(\mathrm{MW} / \mathrm{m}^{2}\right)$ & 0.15 & 0.19 & 0.92 \\
\hline $\begin{array}{l}\text { Diverter Loading } \\
\mathrm{P}_{\mathrm{DIV}} / \mathrm{R}_{0}(\mathrm{MW} / \mathrm{m})\end{array}$ & 7.1 & 10.4 & 25.8 \\
\hline
\end{tabular}

The main technologies needed to fulfill CFETR EC mission are $170 \mathrm{GHz} / 230 \mathrm{GHz}$ gyrotrons, long distance transmission, power supply, control and protection system and integrated antenna.

Design of $170 \mathrm{GHz}$ gyrotron is finished. Key components R\&D started 1-2 years ago, such as helium-free magnet, transmission line, and gyrotron itself. The first step is to develop a gyrotron shown in Fig. 1 with $1 \mathrm{MW}$ power and 5-10 s pulse length at $140 / 170 \mathrm{GHz}$ within next 3-5 years. The following step is to develop the CW $1 \mathrm{MW}$ gyrotron at $170 \mathrm{GHz}$ and $230 \mathrm{GHz}$. The assembly and commission of the whole system for short pulse system will begin before the end of 2017. The other key components for $\mathrm{CW}$ operation, such as diamond window, MOU box and damping load are under design.
Fig. 1. Short pulse $1 \mathrm{MW}$ gyrotron

The key sub-system is the antenna. Two options are under concept design-which based on current developments of microwave antenna for ITER ECRH system. One is top window launcher and another one is the mid-plane antenna shown in Fig. 2. Due to the limitation of space, beam combinationwill be used. 20 transmission

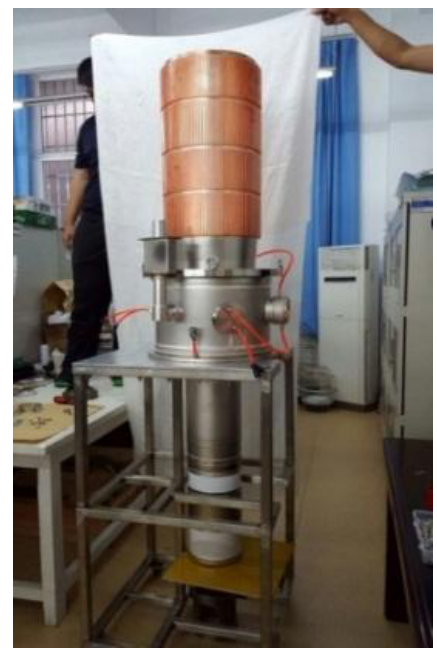
lines which transfer $1 \mathrm{MW}$ power each from gyrotron are combined into the mid-plan port. By combine 5 units into one which handle $5 \mathrm{MW}$ per mirror unit. Steering mechanism similar with that used in EAST will be adopted to have capacity for change the power deposition position and real time NTM suppression. All components inside port are actively cooled with full shielding function. The first steering mirrors are equipped with shutter for plasma contamination during plasma discharge cleaning.

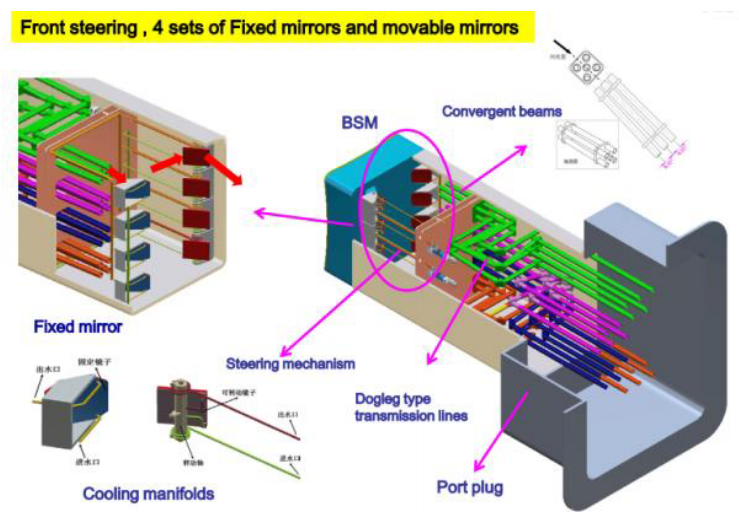

Fig. 2. Concept design for mid-plan port antenna

The detailed physical modeling, concept design, research and development activities including R\&D on long transmission line, helium free magnet, gyrotron for aiming high performance steady state operation in CFETR, will be introduced in this paper.

\section{References}

1. Y. Tao Song, et. Al., IEEE TRANS. ON PLAS. SCI., VOL. 42, 495(2014)

2. B.N. Wan et. al., IEEE TRANS. ON PLAS. SCI Vol. 42, 503(2014)

3. V. Chan, A. Costley, Nuclear Fusion, 2015, 55(2)

4. H.D. Xu, X.J. Wang, F.K. Liu et. al., Plasma Science and Technology, Vol.18, (2016) 442

5. Yunying Tang, Xiaojie WangFukun Liu, et. al., Fusion Engineering and Design, Vol. 89, Issue 6, (2014) 847-852.

6. Yunying Tang, Xiaojie WangFukun Liu, et. al., Fusion Engineering and Design 94(1), 2015

7. X.J. Wang, F.K. Liu, J.F. Shan, Fusion Engineering \& Design 96-97, 2015, p. 181-186. 